\title{
Relationships between lake water chemistry and benthic macroinvertebrates in the Athabasca Oil Sands Region, Alberta
}

\author{
Brent G. PARSONS*, Shaun A. WATMOUGH ${ }^{1)}$, Peter J. DILLON ${ }^{1)}$ and Keith M. SOMERS ${ }^{1,2)}$ \\ Watershed Ecosystems Graduate Program, Trent University, Peterborough, ON K9J 7B8, Canada \\ ${ }^{1)}$ Environmental and Resource Studies, Trent University, Peterborough, ON K9J 7B8, Canada \\ ${ }^{2)}$ Dorset Environmental Science Centre, Ontario Ministry of the Environment, Dorset, ON P0A 1E0, Canada \\ Present address: 1239 Winhara Road, Gravenhurst, ON P1P 1R1, Canada \\ *e-mail corresponding author: brentparsons@trentu.ca
}

\section{ABSTRACT}

Sulphur and nitrogen emissions in the Athabasca Oil Sands Region (AOSR) are a threat to regional lentic ecosystems. Benthic macroinvertebrates have been used successfully elsewhere to monitor the impacts of acid emissions on water bodies and the opportunity exists to implement a regional lentic biomonitoring program in the AOSR. Metrics are often used to assess the impacts of anthropogenic stressors because they describe biological conditions through a variety of measures. The selection of appropriate metrics is an integral component of any biomonitoring program and it depends on the in situ relationships between water chemistry and benthic macroinvertebrates. In order to establish these relationships we compared lake water chemistry parameters with benthic macroinvertebrate communities and metric scores from 32 lakes in the AOSR through Redundancy Analyses. Lake acidity correlates positively with Hyallelidae and negatively with Chironomidae and Oligochaeta while dissolved organic carbon is also an important determinant of benthic macroinvertebrate community composition. A number of metrics were strongly correlated with lake acidity and the following compositional metrics proved to be the most suitable for monitoring acidification in the AOSR: \% Diptera, \% Oligochaeta, \% EPT, Total Ephemeroptera and Total Trichoptera.

Key words: benthic macroinvertebrates, water chemistry, metrics, oil sands, Redundancy Analysis, Canada

\section{INTRODUCTION}

Oil production in the Athabasca Oil Sands Region (AOSR) has resulted in increased emissions of both sulphur oxides $\left(\mathrm{SO}_{\mathrm{x}}\right)$ and nitrogen oxides $\left(\mathrm{NO}_{\mathrm{x}}\right)$. Emissions are expected to remain high for several decades and could cause acid-sensitive lakes in the region to acidify (Golder 2004; Hazewinkel et al. 2008). A regional biomonitoring program for potential impacts of acidification on terrestrial ecosystems in the region has been developed, but a similar program for lentic ecosystems has not been established and appropriate biological endpoints have not been identified.

Many of the lakes in the AOSR are fishless and benthic macroinvertebrates (BMI) are the most suitable biological indicators to monitor the status of acidification in lakes within the AOSR. Aquatic bioassessments generally provide a more robust evaluation of water quality than water chemistry assessments because water chemistry fluctuations are often short term (Harman 1997) and such changes may be missed in routine monitoring programs. This is particularly relevant in remote areas like the AOSR where it is difficult to continually monitor water chemistry and most sampling is conducted on an annual basis. There have been only a limited number of studies using BMI in lakes within the AOSR and these have generally focussed on establishing baseline conditions and assessing impact through a change in community composition (R.L. \& L. Environ- mental Services 1989; Golder 1996; Parsons et al. 2010, this issue). Only a single study (Golder 2003) has assessed the relationship between BMI and water chemistry in lakes in the AOSR, and this study was limited to just two lakes. If BMI are to be used in the AOSR to monitor water quality it is important to establish their relationships with water chemistry and acidity in particular in order to select the most appropriate metrics for monitoring programs.

Biological metrics have been developed that describe biological conditions from structural and/or functional measures (Karr 1991). Many of these metrics have proven effective at monitoring the effects of anthropogenic acidification on freshwaters (Barbour et al. 1999) but because of the lack of studies in the AOSR, it is not clear which metrics are most sensitive to acidity levels. Appropriate metric selection is essential to successful biomonitoring programs (Barbour et al. 1992), but this is rarely done (Diaz et al. 2004).

This study was designed to establish relationships between lake water chemistry and both BMI taxa and key biological metrics. The information could then be used to improve future lentic biomonitoring programs in the AOSR.

\section{METHODS}

\subsection{Study area}

The AOSR is located approximately 400 kilometres northeast of Edmonton, Alberta and is centered around 
Fort McMurray. The area is part of the expansive Boreal Plains and is characterized by fens and bogs, which are dominated by black spruce (Picea mariana) in the lowland areas, while trembling aspen (Populus tremuloides) and jack pine (Pinus banksiana) forests typify the upland regions. The AOSR lies in a slight depression between the Stony Mountains to the south-east and the Birch Mountains located to the north-west. The lakes in the area are generally small and high in dissolved organic carbon (DOC) due to inputs from surrounding wetlands. Many of the lakes are naturally eutrophic as a result of the input of these nutrient-rich waters.

Mining activities in the AOSR began 40 years ago, but oil production increased dramatically when prices spiked in 2004 (Reynolds 2005). Since output is anticipated to grow steadily due to improving extraction techniques and increasing oil prices (Reynolds 2005; National Energy Board 2006) there are concerns that the resulting emissions may negatively impact the surrounding environment. Technological advances have reduced the emissions of $\mathrm{SO}_{\mathrm{x}}$ released per barrel of oil produced, but the magnitude of production has offset these benefits somewhat and about 100,000 tonnes of $\mathrm{SO}_{2}$ were emitted in 2006 (Golder 2004).

\subsection{Study design}

This study focussed only on lakes that are relatively sensitive to acidification ( $<600 \mu \mathrm{eq} \mathrm{L} \mathrm{L}^{-1}$ of base cations), accessible via floatplane ( $>6 \mathrm{ha}$ ), and small enough $(<1000 \mathrm{ha})$ to be characterized by 5 sampling sites (e.g., Reid et al. 1995). According to these parameters, 32 study lakes were selected out of a dataset of 471 lakes. The study lakes represented both best available condition and most impacted due to the multiple objectives of this study (Parsons et al. 2010, this issue). Prior to sampling there was no information available on substrate or macrophytes in the lakes and so these were not included in the selection criteria.

\subsection{Benthic macroinvertebrate sampling}

The protocol from David et al. (1998) was used for benthic macroinvertebrate sampling (e.g., Reid et al. 1995). Between Aug. 15 and Aug. 28, 2006, five sites in the littoral area of each lake were sampled using a travelling kick-and-sweep method. The littoral area at each site was sampled along several transects $(0-1 \mathrm{~m}$ in length) extending perpendicular from shore to a maximum depth of $1 \mathrm{~m}$. One person kicked and dislodged material as the other followed and collected the benthos and associated sediments with a $500 \mu \mathrm{m}$ mesh "D" net. Each site was sampled for a fixed period of 10 minutes.

The resultant sample was washed through two sieves; one contained $\left(1 \mathrm{~cm}^{2}\right)$ hardware cloth to sieve out large organic debris and the other had $500 \mu \mathrm{m}$ mesh to rinse out fine organic material, clay and silt. Glass jars $(1 \mathrm{~L})$ were filled with the sieved sample and preserved with 70\% isopropyl alcohol. At Trent University, the preserved samples were picked following methods in David et al. (1998). Each sample was randomly subsampled and picked until 100 BMI were removed from the material or a $3 \mathrm{~h}$ time limit was reached. Somers et al. (1998) found that for each site, 100 BMI provided enough statistical power to distinguish littoral BMI communities in small lakes. Each sub-sample was processed in its entirety to ensure that biases, such as the selection of larger BMI, were avoided. The BMI, except for Oligochaeta and Hydracarina, were identified to the taxonomic level of family. Bowman \& Bailey (1997) examined ten BMI data sets and concluded that relatively coarse taxonomic resolution (i.e., family or order) provides a similar description of community patterns to higher taxonomic resolution. Five percent of the samples (i.e., $\mathrm{n}=8$, containing $564 \mathrm{BMI}$ ) were re-identified by Ontario Ministry of the Environment personnel and accuracy was found to be $>92 \%$. The five 100 -count BMI site abundances at each lake were combined into a single 500-count BMI lake score because the five sites that were selected at each lake were in proportion to near-shore habitat in an attempt to accurately characterize each lake (David et al. 1998) and were being related to a single water chemistry measurement. Evaluation of near-shore habitat included qualitative estimates of littoral and riparian substrates and vegetation.

\subsection{Lake water sampling}

Duplicate lake water samples were collected from the middle of each lake at a $10 \mathrm{~cm}$ depth. Samples were filtered through $75 \mu \mathrm{m}$ mesh to remove plankton and debris and stored in both $500 \mathrm{~mL}$ polyethylene jars and borosilicate glass tubes. Water samples were stored on ice after collection and were kept cool until arriving at the laboratory for analysis within two weeks of collection. Water samples were analyzed for alkalinity using a PC-Titration Plus system. Nitrate $\left(\mathrm{NO}_{3}\right)$, ammonium $\left(\mathrm{NH}_{4}\right)$, and total Kjeldahl nitrogen (TKN) were determined by colourimetry using a Pulse Autoanalyzer. Samples for DOC, dissolved carbon (DC), inorganic carbon (IC), plus anions and cations were filtered through $0.45 \mu \mathrm{m}$ nylon filters prior to analysis. Dissolved organic carbon, DC and IC were determined using a Shimadzu TOC-VCPH total organic carbon analyzer. Sulphate and chloride $(\mathrm{Cl})$ were analyzed using a Dionex DX-600 ion chromatograph, while sodium $(\mathrm{Na})$, magnesium $(\mathrm{Mg})$, potassium $(\mathrm{K})$, and calcium (Ca) concentrations were determined by direct aspiration flame atomic absorption spectrometry using a Varian 240FS. Acid neutralizing capacity (ANC) was calculated as follows:

$$
\mathrm{ANC}=\left(\mathrm{NH}_{4}+\mathrm{K}+\mathrm{Mg}+\mathrm{Ca}+\mathrm{Na}\right)-\left(\mathrm{NO}_{3}+\mathrm{Cl}+\mathrm{SO}_{4}\right)
$$

\subsection{Establishing relationships between lake water chemistry and BMI assemblages}

Rare BMI families were defined as those found at $<5 \%$ of sites (e.g., Griffith et al. 2001). All rare families 
were excluded from subsequent analyses because they are often found by chance rather than ecological condition; as such, rare taxa can appear as outliers in ordination analyses and they contribute to random "noise" (Gauch 1982). A forward stepwise multiple regression was calculated using $\log _{10}(\mathrm{x}+1)$-transformed BMI family abundances and z-score water chemistry variables $(\mathrm{pH}$, ALK, DOC, DC, IC, NH4, $\mathrm{NO}_{3}, \mathrm{TKN}, \mathrm{TP}, \mathrm{Na}, \mathrm{K}, \mathrm{Mg}$, $\left.\mathrm{Ca}, \mathrm{Cl}, \mathrm{SO}_{4}, \mathrm{ANC}\right)$ which were standardized using:

$$
X=[(x-\text { mean }) / \mathrm{SD}]
$$

where: $X$ is the standardized value, $x$ is the non-standardized value, mean is the average of the values for each water chemistry parameter and SD is the standard deviation of the values for each water chemistry parameter.

The stepwise multiple regression was performed in Statistica 7 (Statsoft 2004) to identify those water chemistry variables that explained a significant amount of BMI variance $(p<0.05)$.

Detrended Correspondence Analysis (DCA) was used to examine the BMI taxonomic data and to determine if RDA or Canonical Correspondence Analysis would be appropriate to evaluate the association between lake water chemistry and BMI data. The DCA ordination gradient was $<3$ standard deviations $(0.84$ $\mathrm{SD})$ and therefore the linear model associated with RDA was appropriate for this dataset (ter Braak \& Prentice 1988).

The logarithmic transformation was used to reduce the effect of absolute abundances (Gauch 1982) whereas the water chemistry variables were standardized because these variables were measured in a variety of units. In the final ordination analysis, DOC was included even though it did not individually explain a significant amount of variance in the multiple regression $(p=0.20)$ because DOC is found in relatively high concentrations throughout the area; and its relationship with the local biota was desired because it may be affected by acidification and has been proven to be a significant determinant of BMI communities in other studies (Lento et al. 2008). Only water chemistry variables were included in this analysis because lake physical properties were not expected to be affected by $\mathrm{SO}_{\mathrm{x}}$ and $\mathrm{NO}_{\mathrm{x}}$ emissions. The relationships between individual BMI families (response variables) and lake water chemistry (predictor variables) were summarized with RDA using the Biplot add-in for Microsoft Excel (Lipkovich \& Smith 2001). When interpreting the results, only BMI families showing correlations greater than 0.07 with RDA axis 1 and/or 2 were presented in order to focus on dominant relationships.

\subsection{Establishing relationships between lake water chemistry and BMI metrics}

Seventeen biological metrics were chosen to contribute relevant ecological information on the integrity of the communities under study. We wanted the metrics to be commonly used and relatively easy to calculate so that our findings could be applied in biomonitoring programs in the AOSR. Metrics were also selected based on their success in other studies (Barbour et al. 1999; Griffith et al. 2000), and most importantly, appropriateness for the dataset. The biological metrics that were calculated were: abundance; richness measures: Richness, Menihinik richness; compositional measures: \% Ephemeroptera, \% Plecoptera and \% Trichoptera (EPT), total Ephemeroptera, total Trichoptera, \% Diptera, \% Oligochaeta, \% Oligochaeta and Hirudinea, dominance, evenness, equitability and Hilsenhoff Modified Biotic Index (HBI); diversity measures: Margalef diversity, Simpsons diversity and Shannon-Wiener diversity. Some metrics were not considered because they require a finer taxonomic resolution than family to be calculated accurately (e.g., functional feeding groups).

The biological metric scores were standardized because they are represented in a variety of scales. The same transformed water chemistry data was used as in the previous analysis. The relationships between BMI metrics (response variables) and lake water chemistry (predictor variables) were again summarized with RDA using the Biplot add-in for Microsoft Excel.

\section{RESULTS}

\subsection{Benthic macroinvertebrates in the AOSR lakes}

There were 13,022 BMI and 45 BMI families collected in total, 16 families which were considered rare as they appeared at $<5 \%$ of sites. These rare families were: Chrysomelidae, Elmidae, Gyrinidae, Haliplidae, Tipulidae, Heptageniidae, Placobdellidae, Sialidae, Hydrobiidae, Lymnaeidae, Brachycentridae, Helicopsychidae, Hydropsychidae, Hydroptilidae, Lepidostomatidae and Limnephilidae. Abundance ranged from 144 to 500 , while richness varied between 7 and 20 families per lake (Tab. 1). The BMI communities were dominated by Hyalellidae, Chironomidae and Sphaeriidae with mean percentage abundance values of 33.1, 30.6 and 10.0, respectively, but BMI composition among lakes ranged considerably (Tab. 1). EPT families were sparse but also varied considerably among study lakes (Tab. 1).

Tab. 1. A summary of the dominant benthic macroinvertebrate community patterns in the 32 study lakes. ${ }^{1)}$ EPT = Ephemeroptera, Plecoptera and Trichoptera.

\begin{tabular}{lccc}
\hline & Mean & Median & Range \\
\hline Abundance & 363 & 378 & $114-500$ \\
Taxa Richness & 13.7 & 14.0 & $7-20$ \\
\% Hyalellidae & 33.1 & 33.8 & $0.0-31.4$ \\
\% Chironomidae & 30.6 & 25.1 & $2.2-81.1$ \\
\% Sphaeriidae & 10.0 & 5.8 & $0.0-47.5$ \\
\% EPT $^{1)}$ & 9.4 & 4.8 & $0.0-40.4$ \\
\hline
\end{tabular}




\subsection{Lake water chemistry}

The mean lake $\mathrm{pH}$ was 6.4 , but ranged from 4.6 to 8.0 (Tab. 2). The mean lake DOC concentration (20.5 $\mathrm{mg} \mathrm{\textrm {L } ^ { - 1 }}$ ) was high and concentrations ranged between $7.1 \mathrm{mg} \mathrm{L}^{-1}$ and $52.4 \mathrm{mg} \mathrm{L}^{-1}$ (Tab. 2). The mean ANC, ALK and Ca concentrations were $282 \mu \mathrm{eq} \mathrm{L}^{-1}, 8.2 \mathrm{mg}$ $\mathrm{L}^{-1}$ and $3.2 \mathrm{mg} \mathrm{L}^{-1}$, respectively, but as with other chemical parameters there was considerable variation among the study lakes (Tab. 2).

Tab. 2. A summary of lake water chemistry results from one mid-lake sample collected from each of the 32 study lakes. ${ }^{1)}$ ALK represents total alkalinity as measured on a PC-Titration Plus system; ${ }^{2)}$ ANC values were calculated as follows: $\left(\mathrm{NH}_{4}+\mathrm{K}+\mathrm{Mg}+\mathrm{Ca}+\mathrm{Na}\right)-\left(\mathrm{NO}_{3}+\mathrm{Cl}+\mathrm{SO}_{4}\right)$.

\begin{tabular}{|c|c|c|c|}
\hline Parameter & Mean & Median & Range \\
\hline $\mathrm{pH}$ & 6.44 & 6.60 & $4.60-8.00$ \\
\hline $\operatorname{ALK}^{1)}\left(\mathrm{mg} \mathrm{L}^{-1}\right)$ & 8.16 & 8.00 & $-0.30-28.20$ \\
\hline $\mathrm{ANC}^{2)}\left(\mu \mathrm{eq} \mathrm{L}^{-1}\right)$ & 282 & 289 & $68-551$ \\
\hline $\mathrm{Ca}\left(\mathrm{mg} \mathrm{L}^{-1}\right)$ & 3.15 & 2.90 & $0.80-6.20$ \\
\hline $\mathrm{DOC}\left(\mathrm{mg} \mathrm{L}^{-1}\right)$ & 20.5 & 16.9 & $7.1-52.4$ \\
\hline $\mathrm{SO}_{4}\left(\mathrm{mg} \mathrm{L}^{-1}\right)$ & 1.54 & 0.90 & $0.00-6.30$ \\
\hline $\mathrm{NO}_{3}\left(\mu \mathrm{g} \mathrm{L}^{-1}\right)$ & 20.4 & 14.2 & $5.8-120.0$ \\
\hline $\mathrm{NH}_{4}\left(\mu \mathrm{g} \mathrm{L}^{-1}\right)$ & 107.0 & 45.2 & $8.3-598.0$ \\
\hline $\operatorname{TKN}\left(\mu \mathrm{g} \mathrm{L}^{-1}\right)$ & 665 & 551 & $163-1790$ \\
\hline $\mathrm{TP}\left(\mu \mathrm{g} \mathrm{L}^{-1}\right)$ & 58.0 & 46.9 & $12.2-198.0$ \\
\hline
\end{tabular}

\subsection{Establishing relationships between lake water chemistry and BMI assemblages}

A forward stepwise multiple regression on lake water chemistry data identified 5 variables $(\mathrm{pH}, \mathrm{ALK}$, $\mathrm{NH}_{4}, \mathrm{SO}_{4}$ and $\mathrm{ANC}$ ) that explained a significant amount of variance $(p<0.05)$ in BMI abundances. These chemistry variables were included in the RDA because of their ability to account for BMI composition and to avoid multicollinearity.

The first two components of the RDA explained $80.8 \%$ of BMI variation and subsequent components did not highlight any interpretable relationships between BMI composition and lake water chemistry. The first RDA axis was positively correlated with lake $\mathrm{pH}(r=$ $0.97), \operatorname{ALK}(r=0.79)$ and ANC $(r=0.74)$, which are all indicators of lake acidity (Fig. 1). Hyalellidae $(r=0.87)$ and Gammaridae $(r=0.24)$ also correlated positively with the acidity gradient exhibited by RDA 1 while Oligochaeta $(r=-0.23)$ and Chironomidae $(r=-0.22)$ were associated with low pH, ALK and ANC (Fig. 1).

Dissolved organic carbon was negatively correlated with RDA axis $2(r=-0.82)$, while Dytiscidae $(r=$ $0.36)$, Leptophlebidae $(r=0.44)$, Corixidae $(r=0.47)$, Sphaeriidae $(r=0.34)$ and Leptoceridae $(r=0.31)$ were positively correlated with RDA axis 2 (Fig. 2).

\subsection{Establishing relationships between lake water chemistry and BMI metrics}

The first two components of the RDA were retained for analysis because they explained $85.2 \%$ of BMI metric score variation. Additional axes did not provide fur- ther insight into relationships between BMI metric scores and water chemistry. The first RDA axis was positively correlated with $\mathrm{pH}(r=0.62)$, ALK $(r=0.65)$ and ANC $(r=0.82)$ (Fig. 2). These acidity indicators were also negatively correlated with RDA axis $2: \mathrm{pH}(r$ $=-0.72)$, ALK $(r=-0.32)$ and ANC $(r=-0.06)$ (Fig. $2)$. The metrics showing the most similar correlations with RDA axes 1 and 2 were: \% Diptera (RDA 1: $r=-$ 0.25 , RDA 2: $r=0.45), \%$ Oligochaeta $(r=-0.31, r=$ $0.29), \%$ Oligochaeta and Hirudinea $(r=-0.23, r=$ $0.26), \%$ EPT $(r=-0.31, r=0.10)$, Total Ephemeroptera $(r=-0.16, r=0.00)$, Total Trichoptera $(r=-0.40, r$ $=0.01)$, HBI Scores $(r=0.41, r=-0.05)$ and Abundance $(r=0.16, r=0.24)$ (Fig. 2).

Dissolved organic carbon was positively correlated with both RDA axis $1(r=0.41)$ and axis $2(0.49)$ (Fig. $2)$. Many richness and diversity metrics contained strong correlations with RDA axis 1 and 2: Dominance (RDA 1: $r=0.14$, RDA 2: $r=0.24)$, Richness $(r=-$ $0.16, r=-0.34)$, Shannon Diversity $(r=-0.21, r=-$ $0.30)$, Simpson's Diversity $(r=-0.14, r=-0.27)$, Margalef Diversity $(r=-0.18, r=-0.26)$ and Equitability $(r$ $=-0.18, r=-0.23$ ) (Fig. 2).

\section{DISCUSSION}

The distribution of BMI is controlled by factors other than water chemistry such as habitat characteristics, sediment quality, sediment grain size, and by biological factors such as competition and predation (Peeters et al. 2004). These factors were not included in this study because they are not expected to be directly impacted by atmospheric emissions and the chemical parameters alone described a very high percentage of variation in BMI taxa and metrics.

\subsection{Benthic macroinvertebrates}

The BMI collected in the AOSR were dominated by Hyalellidae, Chironomidae, and Sphaeriidae. Previous lentic bioassessments in the AOSR have also reported that Chironomidae dominate the benthos while Hyalellidae and Sphaeriidae are also common (Tripp \& Tsui 1980; R.L. \& L. Environmental Services 1989; Golder 2003). Many lakes in the AOSR are shallow enough to freeze completely from the surface to the sediment in the winter, causing anoxic conditions that favour Chironomidae (Noton \& Chymko 1975). Hyalellidae are likely common in the AOSR because they feed on organic material and lakes in the region are generally alkaline (France 1992). Sphaeriidae are one of the most common and abundant BMI and they are most likely widespread in the AOSR because the lakes contain sufficient $\mathrm{Ca}$ concentrations for shell creation (Resh \& Rosenberg 1984). Plecoptera were absent and Ephemeroptera and Trichoptera were sparse in the collections. This is consistent with previous studies which found EPT to be either absent (Syncrude 1975) or in low abundance (Golder 2003) in lakes in the AOSR. 


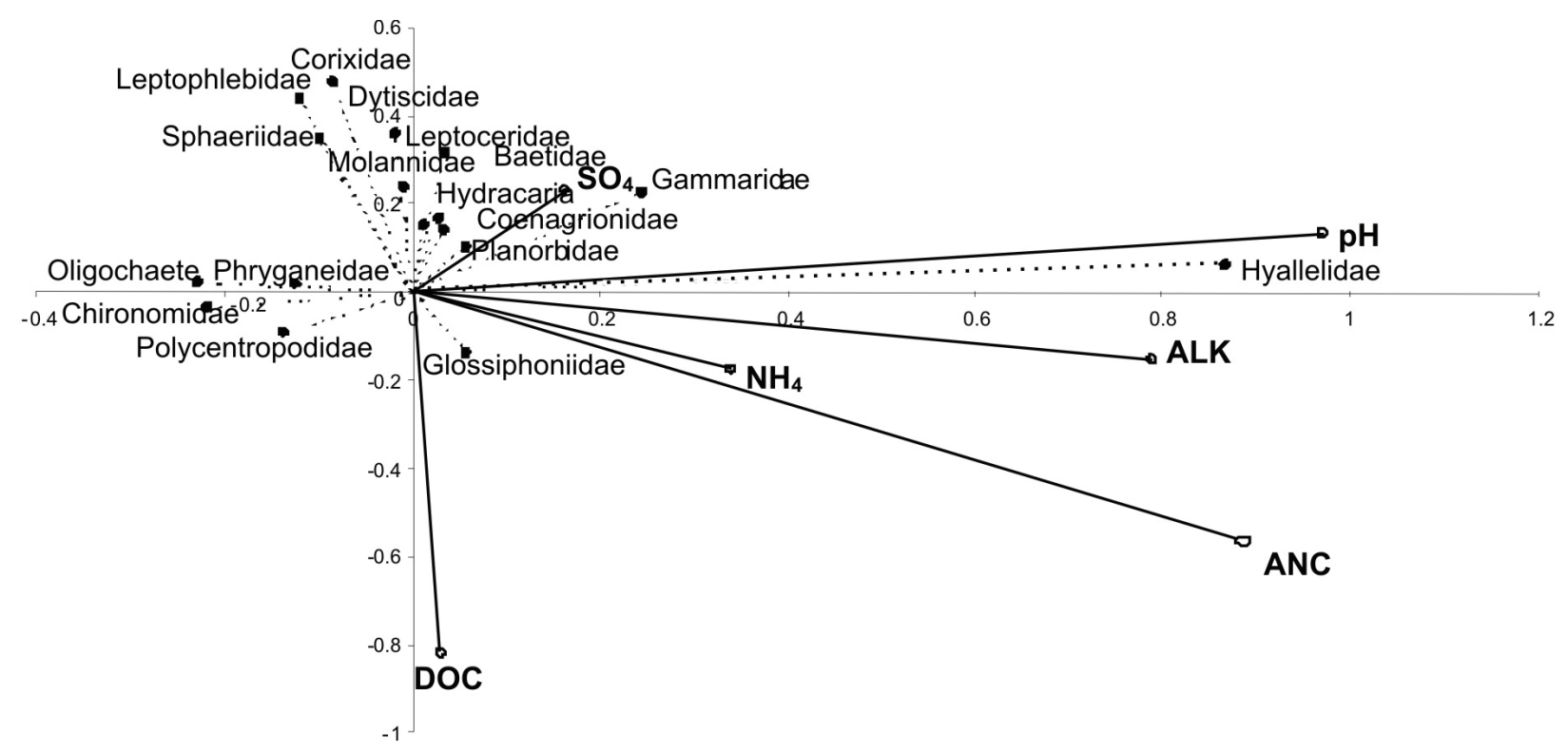

Fig. 1. The association exhibited by the RDA between lake water chemistry and benthic macroinvertebrates. Only the 17 benthic macroinvertebrate taxa showing correlations greater than 0.07 with RDA axis 1 and/or 2 are presented in the plot.

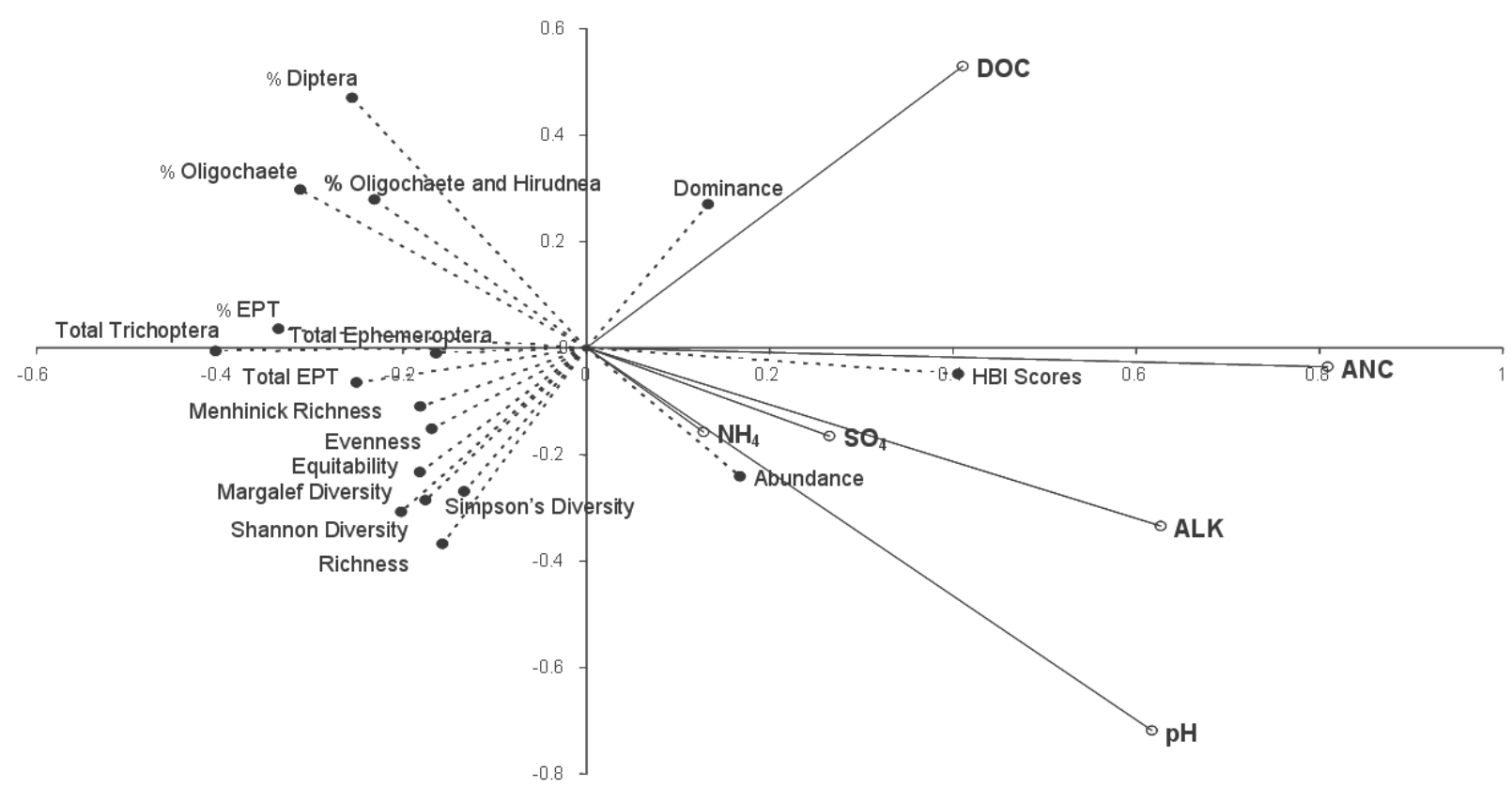

Fig. 2. The association exhibited by the RDA between predictor variables (lake water chemistry) and response variables (metric scores) that were calculated from benthic macroinvertebrate compositional data.

Ephemeroptera, Plecoptera and Trichoptera are likely uncommon because most lakes in the AOSR are known to have low levels of dissolved oxygen and these taxa are particularly sensitive to this (Resh \& Rosenberg 1984). Dissolved oxygen was not included in the water chemistry analysis because the sampling methodology used would not characterize it properly because of temporal and within lake variability.

\subsection{Lake water chemistry}

Previous limnological studies of lentic environments in northern Alberta reported high morphometric and chemical variability between lakes and attributed it to variable geology and drainage characteristics (Halsey et al. 1997; Moser et al. 1998). Shale is the dominant bedrock in the AOSR and its impervious nature and the low 
groundwater gradient often combine to form peatlands and muskeg lakes (Drake 1970). Consequently, the acidity of lakes in the region is influenced by two main factors; one is the contribution of base cations from the surrounding catchment (Siegel et al. 2006) and the other is the input of DOC from the abundant wetlands in the region (Halsey et al. 1997).

\subsection{Establishing relationships between lake water chemistry and BMI assemblages}

The first two components of the RDA explained $80.8 \%$ of BMI variation, which is extremely high compared with other similar studies (e.g., Peeters et al. 2004; Lento et al. 2008). Benthic macroinvertebrate communities in the AOSR are strongly influenced by lake acidity and DOC. Lento et al. (2008) and Hogsden \& Vinebrooke (2005) also found that $\mathrm{pH}$ and DOC are important determinants of BMI community composition. Dissolved organic carbon has numerous interactions with other water quality parameters (Kullberg et al. 1993), including acidity, yet little is known how it affects BMI during acidification (Schartau et al. 2008).

Hyalellidae were more common in less acidic lakes, while Chironomidae and oligochaete families were more common in acidic lakes. Benthic macroinvertebrates are known to be sensitive to acidification and these relationships have been observed elsewhere (e.g., Clenaghan et al. 1998; Buss et al. 2002; Sandin et al. 2003). Amphipods are often used as indicators of lake acidity (e.g., Keller et al. 1992; Lonergan \& Rasmussen 1996; Lento et al. 2008) because they are more sensitive to acidic conditions than most BMI (Resh \& Rosenberg 1984). Similarly, chironomids and oligochaetes are generally associated with more acidic lakes because they contain genera that are both tolerant of acidic conditions and able to colonize rapidly when other groups are depopulated (Resh \& Rosenberg 1984; Buss et al. 2002; Lento et al. 2008). Also, the acidic lakes were generally found in muskeg dominated areas where abundant organic substrates provide habitat and food resources for chironomids and oligochaetes (Moroz 1994). The other marked trend between water chemistry and BMI is that populations of Dytiscidae, Corixidae, Sphaeriidae, Leptophlebidae and Leptoceridae declined with elevated DOC concentrations. Dissolved organic carbon is an important determinant of BMI (Hogsden \& Vinebrooke 2005 ) but the association is only rarely studied (Lento et al. 2008). The relationship between DOC and BMI is unclear because it has both direct and indirect impacts on biota. It affects the availability of metals and interferes with osmoregulation (Kullberg et al. 1993) but Schartau et al. (2008) claimed it has positive effects as it buffers the effects of lowered acidity on BMI.

The natural variability in acidity and DOC provides a challenge to bioassessments in the AOSR because these chemical parameters are important determinants of BMI composition (Parsons et al. 2010, this issue). An acidity gradient was produced in the RDA and indicator species are prevalent in both high (Amphipoda) and low (Chironomidae, Oligochaeta) $\mathrm{pH}$ waters. These results suggest that any decreases of lake $\mathrm{pH}$ in the AOSR should generally result in a decreased abundance of amphipods and increase in Chironomidae and Oligochaeta.

\subsection{Establishing a relationship between lake water chemistry and BMI metrics}

The total variance explained by the first two components of the RDA was $85.2 \%$, which is generally higher than BMI taxa in similar studies (Buss et al. 2002; Johnson \& Goedkoop 2002). Metric selection is stressed in the "multimetric" approach but metrics are also included in a variety of multivariate analyses such as Test Site Analysis (TSA) and Multivariate Analysis of Variance (MANOVA). According to the RDA, lake acidity should be monitored with: \% Diptera, \% Oligochaeta, \% Oligochaeta and Hirudinea, \% EPT, Total Ephemeroptera, Total Trichoptera, the Hilsenhoff Biotic Index and/or Abundance, because the slopes of these metrics were aligned with the acidity gradient.

Percent Diptera, \% Oligochaeta, \% Oligochaeta and Hirudinea are all negatively correlated with $\mathrm{pH}$ while $\mathrm{BMI}$ abundance is positively correlated with $\mathrm{pH}$. These metrics have the advantages that constituent taxa are common in lakes within the AOSR; the metrics are both easy to calculate and analyze; and the are readily interpretable and easy to communicate. Also, the ecological understanding of Diptera and Oligochaeta and their relationships with acidity have been established. BMI abundance is correlated positively with $\mathrm{pH}$ but abundance measures can be misleading if not interpreted in conjunction with other information such as BMI community composition. For example, acidification can lead to the disappearance of acid-sensitive species but the abundance of tolerant species can increase exponentially due to the lack of interspecific competition. Clenaghan et al. (1998) found that BMI abundance increased with $\mathrm{pH}$, but there are many contributing abiotic and biotic factors that can affect this relationship, making interpretation of these data difficult (Vinebrooke \& Graham 1997). We suggest that abundance could be used to monitor acidification in the AOSR but only if careful attention is paid to taxonomic data.

Percent EPT, Total Ephemeroptera and Total Trichoptera were negatively correlated with ANC while the Hilsenhoff Biotic Index was positively correlated with ANC. The metrics involving Ephemeroptera and/or Trichoptera are often used to assess the impacts of acidification (Sandin \& Johnson 2000) or recovery from acidification (Schartau et al. 2008). Unfortunately, these species are rare in some lakes in the AOSR, specifically in lakes with high DOC concentrations and organic substrates, and as such are not recommended for monitoring these types of lakes as the power of analysis would 
be severely limited by sample size. The Hilsenhoff Biotic Index was developed in Wisconsin rivers to monitor nutrient enrichment (Hilsenhoff 1988). Acid neutralizing capacity reflects the role of nutrients and organic acids associated with DOC. Although the HBI wasn't developed for monitoring acidification it appears to be diagnostic of the acidity gradient and could be applied in the AOSR.

Dominance, Richness, Shannon Diversity, Simpson's Diversity, Margalef Diversity and Equitability appear to be the suitable BMI indices for monitoring DOC in the AOSR. There is evidence that DOC concentrations are changing in many parts of Europe and North America, which appear to be related to changes in acid deposition (Monteith et al. 2007). It is also a significant determinant of BMI composition and must be considered when monitoring the biological response of lakes to acid deposition in the AOSR. Lake acidity and benthic macroinvertebrates are greatly affected by DOC in the AOSR. In order to accurately monitor acidification these relationships have to be taken into account (e.g., Schartau et al. 2008) because ecosystem level information is important when evaluating acidification (Lonergan \& Rasmussen 1996). Dissolved organic carbon has been used in combination with acidity as a measure of anthropogenically-induced acidification (Lydersen et al. 2004). In the AOSR it seems that applying DOC as a covariate in analysis would allow for acidification to be better analyzed (e.g., Schartau et al. 2008).

\section{CONCLUSIONS}

Benthic macroinvertebrate composition was strongly affected by lake water chemistry in the study lakes. Hyallelidae are representative of less acidic conditions while Chironomidae and Oligochaeta are indicative of more acidic conditions. Biological metrics provide a more powerful means of assessment by encompassing multiple aspects of assemblages (Karr et al. 1986). The metrics that were most strongly related to lake $\mathrm{pH}$ values were \% Diptera, \% Oligochaeta, \% Oligochaeta and Hirudinea, and Abundance, while \% EPT, Total Trichoptera and Total Ephemeroptera and the Hilsenhoff Biotic Index are most strongly related to lake ANC. Abundance measures can be misleading and HBI was not designed to monitor acidification but with appropriate examination of compositional data these measures could be used successfully. Overall these findings increase the feasibility of developing a successful lentic biomonitoring program in the AOSR where chemical sampling is infrequent and at present, human impact is small compared with natural variability in lake chemistry (Parsons et al. 2010, this issue).

\section{ACKNOWLEDGEMENTS}

We would like to thank Tim Seabert, Angela Adkinson, Colin Whitfield and Preston McEachern for assis- tance during field work and Heather Broadbent, Joe Findeis, Scott Barker, Kyle Moorhouse and Ellen McLeod for help with laboratory work. Thanks to Ron Reid, Nicole Dmytrow and Chris Jones of the Dorset Environmental Science Centre for training and $\mathrm{J}$. Aherne and J. Potter for technical assistance. Alberta Environment provided logistical support during the field season and it was greatly appreciated. This work was financially supported by the Cumulative Environmental Management Association and a Collaborative Research and Development Grant from the Natural Sciences and Engineering Research Council awarded to SAW and PJD.

\section{REFERENCES}

Barbour, M.T., J. Gerritsen, B.D. Snyder \& J.B. Stribling. 1999. Rapid bioassessment protocols for use in streams and wadeable rivers: periphyton, benthic macroinvertebrates and fish. 2nd Ed. U.S. Environmental Protection Agency, Office of Water, Washington, D.C. EPA 841-B99-002.

Barbour, M.T., J.L. Plafkin, B.P. Bradley, C.G. Graves \& R.W. Wiseman. 1992. Evaluation of EPA's rapid bioassessment benthic metrics: metric redundancy and variability among reference sites. Environ. Tox. Chem., 11: 437-449.

Bowman, M.F. \& R.C. Bailey. 1997. Does taxonomic resolution affect the multivariate description of the structure of freshwater benthic macroinvertebrate communities? Can. J. Fish. Aquatic. Sci., 54: 1802-1807.

Buss, D.F., D.F. Baptista, M.P. Silveira, J.L. Nessimian \& L.F.M. Dorville. 2002. Influence of water chemistry and environmental degradation on macroinvertebrate assemblages in a river basin in south-east Brazil. Hydrobiologia, 481: $125-136$.

Clenaghan, C., P.S. Giller, H. O'Halloran \& R. Hernan. 1998. Stream macroinvertebrate communities in a conifer-afforested catchment in Ireland: relationships to physicochemical and biotic factors. Freshwat. Biol., 40: 175-193.

David, S.M., K.M. Somers, R.A. Reid, R.J. Hall \& R.E. Girard. 1998. Sampling protocols for the rapid bioassessment of streams and lakes using benthic macroinvertebrates. 2nd Ed. Ontario Ministry of the Environment Data Report: 29pp.

Diaz, R.J., M. Solan \& R.M. Valente. 2004. A review of approaches for classifying benthic habitats and evaluating habitat quality. J. Environ. Manage., 73: 165-181.

Drake, J.J. 1970. The geomorphic implications of geo-hydrology of gypsum karst areas. MSc Thesis. McMaster University, Hamilton, ON: 90 pp.

Environment Canada. 2004. Canadian acid deposition science assessment. Meteorological Service of Canada: 479 pp.

France, R.L. 1992. Biogeographical variation in size-specific fecundity of the amphipod Hyalella azteca. Crustaceana, 62: $240-248$.

Gauch, H.G. 1982. Multivariate Analysis in Community Ecology. Cambridge University Press, New York: 435 pp.

Golder Associates Ltd. 1996. Shipyard Lake environmental baseline study. Suncor Inc., Oil sands Group. Fort McMurray, AB: $22 \mathrm{pp}$.

Golder Associates Ltd. 2003. RAMP 5 year report. Regional Aquatic Monitoring Program, Calgary, AB.

Golder Associates Ltd. 2004. A summary of work for the management of acid emissions in the oil sands. Background information for the dynamic modelling of acid emissions. Workshop \#2. 
Griffith, M.B., P.K. Kaufmann, A.T. Herlihy \& B.H. Hill. 2001. Analysis of macroinvertebrate assemblages in relation to environmental gradients in Rocky Mountain streams. Ecol. Appl., 11: 489-505.

Halsey, L.A., D.H. Vitt \& D.O. Trew. 1997. Influence of peatlands on the acidity of lakes in northeastern Alberta, Canada. Water Air Soil Pollut., 96: 17-38.

Harman, W.M. 1997. Ostego Lake macrobenthos communities between 1968 and 1993: indicators of decreasing water quality. J. Freshwat. Ecol., 12: 465-476.

Hazewinkel, R.R.O., A.P. Wolfe, S. Pla, C. Curtis \& K. Hedley. 2008. Have atmospheric emissions from Athabasca Oil Sands impacted lakes in northeastern Alberta? Can. J. Fish. Aquat. Sci., 65: 1554-1567.

Hilsenhoff, W. 1988. Rapid field assessment of organic pollution with a family-level biotic index. J. N. Am. Benthol. Soc., 7: 65-58.

Hogsden, K.L. \& R.D. Vinebrooke. 2006. Environmental predictors of benthic consumers and autotrophic communities along a recovery gradient. Can. J. Fish. Aquat. Sci., 62: 2226-2239.

Johnson, R.K. \& W. Goedkoop. 2008. Littoral macroinvertebrate communities: spatial scale and ecological relationships. Freshwat. Biol., 47: 1840-1854.

Karr, J.R. 1991. Biological integrity: a long-neglected aspect of water resource management. Ecol. Appl., 1: 66-84.

Keller, W., J.R. Pitbaldo \& J. Carbone. 1992. Chemical responses of acidic lakes in the Sudbury, Ontario, area to reduced smelter emissions, 1981-89. Can. J. Fish. Aquat. Sci., 29: 25-32.

Kullberg, A., K.H. Bishop, A. Hargeby \& M. Jansson. 1993. The ecological significance of dissolved organic carbon in acidified waters. Ambio, 22: 331-337.

Lento, J., P.J. Dillon, K.M. Somers \& R.A. Reid. 2008. Changes in littoral benthic macroinvertebrate communities in relation to water chemistry in 17 Precambrian Shield Lakes. Can. J. Fish. Aquat. Sci., 65: 906-918.

Lipkovich, I. \& E.P. Smith. 2001. Biplot and singular value decomposition macros for Excel. J. Stat. Soft., 7: 1-13.

Lonergan, S.P. \& J.B. Rasmussen. 1996. A multi-taxonomic indicator of acidification: isolating the effects of $\mathrm{pH}$ from other water-chemistry variables. Can. J. Fish. Aquat. Sci., 53: $1778-1787$.

Lydersen, E., T. Larssen \& E. Fjeld. 2004. The influence of total organic carbon (TOC) on the relationship between acid neutralizing capacity (ANC) and fish status in Norwegian lakes, Sci. Tot. Environ., 326: 63-69.

Monteith, D. T., J.L. Stoddard, C.D. Evans, H.A. de Wit, M. Forsius, T. Hogasen, A. Wilander, B.L. Skjelkvale, D.S. Jeffries, J. Vuorenmaa, B. Keller, J. Kopacek \& J. Vesely. 2007. Dissolved organic carbon trends resulting from changes in atmospheric deposition chemistry. Nature, 450: 537-540.

Moroz, T.G. 1994. Aquatic oligochaeta of the Dnieper-Bug estuary system. Hydrobiologia, 279: 133-138.

Moser, K.A., J.P. Smol, D.S. Lean \& G.M. MacDonald. 1998. Physical and chemical limnology of northern boreal lakes. Can. J. Fish. Aquat. Sci., 377: 25-43.

National Energy Board. 2006. Canada's oil sands, opportunites and challenges to 2015: an overview. Canadian Energy Assessment, Canada: 85 pp.
Noton, L.R \& N.R. Chymko. 1978. Water quality and aquatic resources of the Beaver Creek Diversion System. Environmental Research Monograph, Syncrude Canada Ltd.: $350 \mathrm{pp}$.

Osenberg, C.W., R.J. Schmitt, S.J. Holbrook, K.E. Abu-Saba \& A.R. Flegal. 1994. Detection of environmental impacts: Natural variability, effect Size, and power analysis, Ecol. Appl., 4: 16-30.

Parsons, B.P., S.A. Watmough, P.J. Dillon \& K.M. Somers. 2010. A bioassessment of lakes in the Athabasca Oil Sands Region, Alberta, using benthic macroinvertebrates. J. Limnol., 69(Suppl. 1): 105-117. DOI: 10.3274/JL10-69S1-11.

Peeters E.T.H.M., R. Gylstra \& J.H. Vos. 2004. Benthic macroinvertebrate community structure in relation to food and environmental variables. Hydrobiologia, 519: 103115.

R.L. \& L. Environmental Services Ltd. 1989. OSLO Project: water quality and fisheries resources baseline studies. BOVAR Environmental Services. Edmonton, AB: 127 pp.

Reid R.A., K.M. Somers \& S.M. David. 1995. Spatial and temporal variation in littoral-zone benthic invertebrates from three south-central Ontario lakes. Can. J. Fish. Aquat. Sci., 52: 1406-1420.

Resh, V.H. \& D.M. Rosenberg. 1984. The ecology of aquatic insects. Praeger, New York: 625 pp.

Reynolds, D.B. 2005. The economic of oil definitions: the case of Canada's oil sands. OPEC Review, 29: 51-73.

Sandin, L. 2003. Benthic macroinvertebrates in Swedish streams: Community, structure, taxon richness and environmental relations. Ecography, 26: 269-282.

Sandin, L. \& R.K. Johnson. 2000. Ecoregions and benthic macroinvertebrate assemblages of Swedish streams. J. N. Am. Benthol. Soc., 19: 462-474.

Schartau, A.K., S.J. Moe, L. Sandin, B. McFarland \& G. G. Raddum. 2008. Macroinvertebrate indicators of lake acidification: analysis of monitoring data from UK, Norway and Sweden. Aquat. Ecol., 42: 293-305.

Siegel, D.I., P.H. Glaser, J. So \& D.R. Janecky. 2006. The dynamic balance between organic acids and circumneutral groundwater in a large boreal peat basin. J. Hydrol., 320: $421-431$.

Somers, K.M., R.R. Reid \& S.M. David. 1998. Rapid biological assessments: how many animals are enough? J. N. Am. Benthol. Soc., 17: 348-358.

StatSoft Inc., 2004. STATISTICA (Data Analysis Software System), Version 7. StatSoft Inc., Tulsa, OK, USA.

Syncrude Ltd. 1975. Baseline environmental studies of Ruth Lake and Poplar Creek. Syncrude Environmental Research Monograph. Calgary, AB.

ter Braak C.J.F. \& I.C. Prentice. 1988. A theory of gradient analysis. Adv. Ecol. Res., 18: 271-317.

Tripp, D.B. \& P.T.P Tsui. 1980. Fisheries and habitat investigations of tributary streams in the southern portion of the AOSERP study area. Volume I. Alberta Environment and Environment Canada, Edmonton, AB: 224 pp.

Vinebrooke, R.D. \& M.D. Graham. 1997. Periphyton assemblages as indicators of recovery in acidified Canadian Shield lakes. Can. J. Fish. Aquat. Sci., 54: 1557-1568. 